\title{
Positive CD63 Basophil Activation Tests Are Common in Children with Chronic Spontaneous Urticaria and Linked to High Disease Activity
}

\author{
Elena Netchiporouk ${ }^{a} \quad$ Linda Moreau $^{a} \quad$ Elham Rahme ${ }^{b} \quad$ Marcus Maurer $^{d}$ \\ Duncan Lejtenyi ${ }^{c}$ Moshe Ben-Shoshan ${ }^{c}$ \\ ${ }^{a}$ Division of Dermatology, ${ }^{b}$ Division of Clinical Epidemiology, Department of Medicine, and ${ }^{\mathrm{C}}$ Division of Allergy \\ and Clinical Immunology, Department of Pediatrics, McGill University Health Centre, Montreal, QC, Canada; \\ ${ }^{\mathrm{d}}$ Department of Dermatology and Allergy, Charité - Universitätsmedizin, Berlin, Germany
}

\section{Keywords}

Chronic spontaneous urticaria $\cdot$ Chronic urticaria $\cdot$ Physical urticaria - Autoimmune urticaria - Basophil activation test · CD63 $\cdot$ CD63 cutoff value

\begin{abstract}
Background: The basophil activation test (BAT) using CD63 expression is a sensitive and specific tool for the diagnostic workup of autoimmune chronic spontaneous urticaria (CSU). The definition of a positive BAT is directly dependent on the reference range and the cutoff values established in control populations. As of now, the pediatric reference range and cutoff values of the CD63 BAT remain to be established. Methods: In this study, we analyzed CD63 expression in 80 children (1-17 years old) without chronic urticaria (i.e., controls) and compared the values to those of a pediatric cohort of 105 CSU patients and 23 physical urticaria (PU) patients. Results: Based on the log-normal distribution of CD63 values in control subjects, the reference range and the cutoff for positive CD63 BAT values was established to be $1.2-1.8 \%(95 \% \mathrm{Cl})$ and $1.8 \%$, respectively. Children with CSU showed significantly elevated and significantly increased BAT values compared to healthy controls (Wilcoxon rank test $p$ value $<0.001)$. In contrast, no difference was found
\end{abstract}

\section{KARGER}

(c) 2016 S. Karger AG, Basel

E-Mail karger@karger.com

www.karger.com/iaa between BAT results in controls and PU patients. In pediatric CSU patients, a higher disease activity was associated with higher BAT values. Conclusions: Our study provides, for the first time, reference and cutoff values for the CD63 BAT in children. Our findings show that positive CD63 BAT are common in children with CSU and linked to a high disease activity.

(c) 2016 S. Karger AG, Basel

\section{Introduction}

Chronic urticaria (CU) is a mast cell-driven disease and it is defined as the recurrent occurrence of transient wheals and/or angioedema for at least 6 weeks. In most cases, hives and angioedema occur spontaneously and are not attributable to a specific trigger (chronic spontaneous urticaria; CSU) [1]. Up to $40 \%$ of adults and children with CSU are considered to have a type II autoimmune basis for their disease [2-4]. In these patients, autoantibodies are held to induce mast cell (and basophil) degranulation. Patients can be screened for the presence of these autoantibodies either in vivo with use of the autologous serum skin test (ASST) or in vitro via the basophil activation test (BAT) [5-9]. 
Basophils represent $<1 \%$ of circulating leukocytes and are the substrate for the BAT [10]. Structurally and functionally, basophils are similar to tissue mast cells, which are central to the pathogenesis of CSU. Similarly to mast cells, basophils express the high-affinity IgE receptor (FceRI) on their surface. Cross-linking of FceRI by IgE and an antigen or an antibody results in cell activation, the release of preformed granules, and the secretion of cytokines, chemokines, and lipid mediators [11].

Upon FceRI-mediated stimulation, basophils also upregulate the expression of distinct activation markers [12]. In 1991, Knol et al. [13] demonstrated that tetraspanin CD63, a cell surface marker, is upregulated on degranulating basophils. It was further shown that basophil activation via FceRI leads to the fusion of CD63-positive secretory granules, which can be measured by flow cytometry and represent an indirect marker of histamine release $[10,14,15]$. BAT using CD63 expression is a sensitive and specific tool for the diagnostic workup of a wide range of IgE-mediated allergies including food and drug allergies [12]. Recently, the BAT has also been shown to correlate with the ASST as well as with the results of basophil histamine release assays (BHRA), and it has been proposed as a reliable functional assay in the diagnosis of autoimmune urticaria [16]. In contrast to the ASST, the BAT: (1) does not bear the risk of accidental infection by injections of autologous serum, (2) is not influenced by the intake of antihistamines, (3) provides quantifiable results, (4) is suited for the monitoring of treatment, (5) can distinguish between patients who express anti-IgE and anti-FceRI antibodies, and (6) can be performed in patients of any age including infants [17-19].

The definition of a positive BAT outcome and the interpretation of BAT results in CSU and other patient populations are directly dependent on the reference values established in control populations, e.g., healthy individuals. Ideally, such control populations should match the patient population in gender and age distribution as well as in the rate of atopic individuals. At present, BAT reference values and cutoff criteria are derived from limited numbers of adults, but they have not yet been determined in children. BAT results in children may be different from those in adults, and pediatric reference values and cutoff criteria are, therefore, needed. The aim of our study was to establish the reference range of CD63 expression-based BAT results in children without CSU, to compare their BAT results with those of pediatric CSU patients and physical urticaria (PU) patients, and to assess the effects of age, gender, ethnicity, atopy, disease activity, and IgE levels on BAT results.

\section{Patients and Methods}

Control Subjects and Patients with CSU or PU

This study was conducted between January 2014 and December 2015 in Montreal, QC, Canada. Subjects were recruited at the allergy and immunology clinic of the Montreal Children's Hospital. The study population included 80 non-CSU control children recruited from established registries in our allergy clinic, 105 children with CSU, and 23 children with PU (Table 1). Data was collected on age, gender, ethnicity, IgE levels, and atopy (asthma, atopic eczema, food allergy, and allergic rhinitis) as previously defined [20].

In addition, for the CSU cohort, we measured disease activity by use of the weekly urticaria activity score (UAS7), the gold standard for assessing CSU activity (based on daily recordings of wheal number and itch intensity) [21].

We excluded patients with an active infection, autoimmune diseases (only for the control group), and a recent allergic reaction and those who were taking drugs that could lead to direct mast cell/ basophil degranulation (e.g., opiates). Patients receiving oral corticosteroids were also not included in this study. For CSU and PU patients, their treatment regimen was not interrupted prior to recruitment.

The study protocol and consent forms were approved by the institutional review board of the McGill University Health Centre and they were in accordance with the guiding principles of the Declaration of Helsinki. Written informed consent was obtained from the children's parents or legal guardians prior to conducting any study-related investigation. In addition, patients older than 7 years were requested to sign an assent form. All data used in this study remained anonymous.

\section{Basophil Activation Test}

A healthy nonatopic volunteer (a 40 year-old male) served as the basophil donor for the entire study. The reactivity of the donor cells was tested by incubation with anti-FceRImAb and Nformyl-methionyl-leucyl-phenylalanine (fMLP) $(50 \mu \mathrm{L}$, Flow Cast ${ }^{\circledR}$; Bühlmann, Switzerland). In order to test the reproducibility of the results, BAT analyses of 46 randomly chosen patients were repeated using basophils from a second healthy nonatopic volunteer donor matched for age and sex. There was no significant difference between the BAT results obtained from basophil donors 1 and 2 (Wilcoxon rank test, $p$ value $=0.9$ ) (online suppl. Table 1; for all online suppl. material, see www. karger.com/doi/10.1159/000451084).

Commercially available BAT kits were purchased from Bühlmann (Flow Cast ${ }^{\circledR}$ ). The CD63 expression on the surface of donor basophils was determined by flow cytometry according to the protocol provided by the company and adapted for use in CSU patients as previously described [17]. Briefly, $50 \mathrm{uL}$ of healthy donor blood was mixed with $50 \mathrm{uL}$ of patients' serum, $100 \mathrm{uL}$ of stimulation buffer (which contains IL-3), and $20 \mathrm{uL}$ of antibody mix (contains fluorescein isothiocyanaten-labeled anti-CD63 antibody and phycoerythrin-labeled anti-CCR3 antibody) and incubated for 30 min at $37^{\circ} \mathrm{C}$. Anti-FceRI antibody $(50 \mu \mathrm{L})$ and N-formyl-methionyl-leucyl-phenylalanine (fMLP; $50 \mu \mathrm{L}$ ) served as positive controls. As a negative control, patients' sera were replaced by $50 \mathrm{uL}$ of stimulation buffer. Basophils were identified by their CCR3 expression on a FACScalibur. The percentage of activated basophils was determined based on the expression of CD63. 
Table 1. Subjects' demographics and clinical characteristics

\begin{tabular}{|c|c|c|c|c|}
\hline & $\begin{array}{l}\text { Controls } \\
(n=80)\end{array}$ & $\begin{array}{l}\text { Controls with outliers } \\
\text { removed }(n=66)\end{array}$ & $\begin{array}{l}\text { CSU patients } \\
(n=105)\end{array}$ & $\begin{array}{l}\text { PU patients } \\
(n=23)\end{array}$ \\
\hline Median age (IQR), years & $10(5$ to 15.0$)$ & $9.5(5$ to 15.0$)$ & $8.0(5.0$ to 12.5$)$ & $11.0(5$ to 16$)$ \\
\hline Male gender, $\%$ & $53.4(42.6$ to 64.9 .0$)$ & $54.5(42.2$ to 66.9$)$ & $48.6(38.9$ to 58.3$)$ & $47.8(25.7$ to 69.9$)$ \\
\hline Caucasian ethnicity, \% & $86.3(78.5$ to 94.0$)$ & $86.4(77.9$ to 94.9$)$ & 65.7 (56.5 to 74.9$)$ & 91.3 (78.9 to 103.8$)$ \\
\hline Atopy, $\%$ & $78.8(70$ to 87.9$)$ & 80.3 (70.5 to 90.2$)$ & $21.9(13.9$ to 30.0$)$ & $26.1(6.7$ to 45.5$)$ \\
\hline Food allergy, \% & $68.8(58.4$ to 79.1$)$ & 69.7 (58.3 to 81.1$)$ & $3.8(0.9$ to 7.5$)$ & $8.7(-3.8$ to 21.2$)$ \\
\hline Hay fever, \% & $3.75(-0.5$ to 8.0$)$ & $4.5(-0.6$ to 9.7$)$ & $6.67(1.8$ to 11.5$)$ & $8.7(-3.8$ to 21.2$)$ \\
\hline Eczema, \% & $12.5(5.1$ to 19.9$)$ & $13.6(5.1$ to 22.1$)$ & $12.4(6.0$ to 18.8$)$ & $17.4(0.63$ to 34.2$)$ \\
\hline Drug allergy, \% & $15.0(7.0$ to 23.0$)$ & $16.7(7.4$ to 25.9$)$ & $3.8(0.9$ to 7.5$)$ & $8.7(-3.8$ to 21.2$)$ \\
\hline Recent positive SPT, $n$ & $33.8(23.1$ to 44.4$)$ & $36.4(24.4$ to 48.3$)$ & 0 & 0 \\
\hline \multicolumn{5}{|l|}{ Type of PU, $n$} \\
\hline Cold & & & & $69.6(49.2$ to 89.9$)$ \\
\hline Median CD63 level (IQR), \% & $1.3(0.5$ to 2.4$)$ & $1.4(0.9$ to 2.6$)$ & $2.1(1.2$ to 5.3$)$ & $1.9(0.9$ to 3.3$)$ \\
\hline Mean IgE level (SD), $\mu \mathrm{g} / \mathrm{L}$ & $1,561.5(2,169.9)$ & $1,690.4(2,308.5)$ & $352.1(526.1)$ & $947.4(1,741.1)$ \\
\hline
\end{tabular}

Values in parentheses are 95\% CI unless otherwise stated. CSU, chronic spontaneous urticarial; PU, physical urticarial; N/A, not applicable; SPT, skin prick test.

\section{Statistical Analyses}

Statistical analyses were conducted using $\mathrm{R}$ version 2.12.0 (2010-10-15). Given the relatively small sample size, the reproducibility of BAT results from different basophil donors was assessed based on the nonparametric Wilcoxon signed rank test with continuity correction. The normality of BAT results in the control population was assessed visually using a histogram as well as by the Kolmogorov-Smirnov test. A box plot was used to identify and exclude outliers. Values $1.5 \times$ the IQR above the third quartile or below the first quartile of control BAT values were considered outliers and removed from the analysis for the calculation of the cutoff value only. This procedure resulted in the exclusion of one outlier of CD63 BAT (natural log of CD63 0.01\%; -4.61 ); 14 patients had this value out of the 80 recruited. Reference values for CD63 in controls were defined by the central 95\% $\mathrm{CI}$ from the obtained log-normal distribution. The cutoff for abnormal (high) CD63 was established as values above the 95th percentile of the rate of $\mathrm{CD}^{+} 3^{+}$cells induced by the non-CSU control patients' sera, similar to published studies in adult CSU [16].

The Wilcoxon rank test was used to compare crude BAT means between the groups (controls, CSU, and PU patients) as it does not require the data to follow a prespecified parametric distribution (e.g., normal). To test for possible variations related to age, gender, ethnicity (Caucasian or non-Caucasian), and atopy (asthma, food allergy, atopic eczema, or hay fever), univariate and multivariate linear regression analyses were performed using a logarithmic data transformation (log-normal distributions) to assess potential confounders.

Basophil Activation Test in Chronic Urticaria
To determine the CD63 cutoff value for predicting disease activity, we used CUTOFF finder software (Charité University) [22]. UAS7 was used to separate CSU patients into those with mild disease (UAS7 <15) and those with moderate to severe disease (UAS7 $\geq 15$ ) according to expert opinion [23].

\section{Results}

\section{Demographic Characteristics and Reference Range of}

BAT Results of Control Children

The current study included 80 control subjects; $53.4 \%$ were male and the median age was 10 years (25\% interquartile [IQ], 5; 75\% IQ, 15). The majority were Caucasians and the most common atopic condition was food allergy (Table 1). Mean IgE levels were 1,562 $\mu \mathrm{g} / \mathrm{L}(640$ $\mathrm{kU} / \mathrm{L}, \mathrm{SD} 889 \mathrm{kU} / \mathrm{L})$. Patient demographic characteristics remained similar after removal of the outliers for the CD63 cutoff calculation (Table 1).

The median percentage of activated basophils as assessed by CD63 expression in the control population was $1.28 \%$ (25\% IQ, 0.50; 75\% IQ, 2.42). The KolmogorovSmirnov test of normality and the histogram (Fig. 1a) indicated that the distribution of CD63 BAT was skewed. Hence, values were converted to the natural logarithmic 


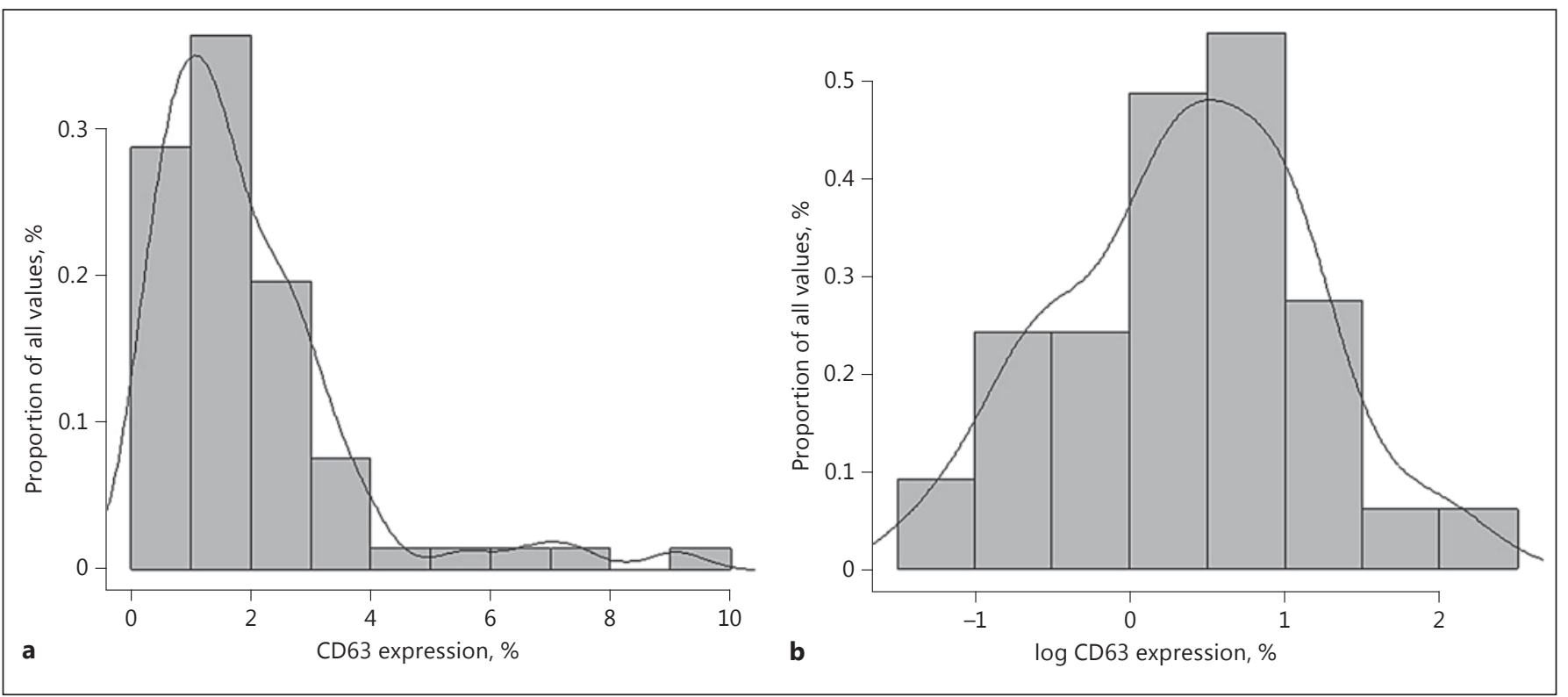

Fig. 1. Distribution of CD63 expression in non-CSU control subjects using numerical (a) and logarithmic (b) scales.

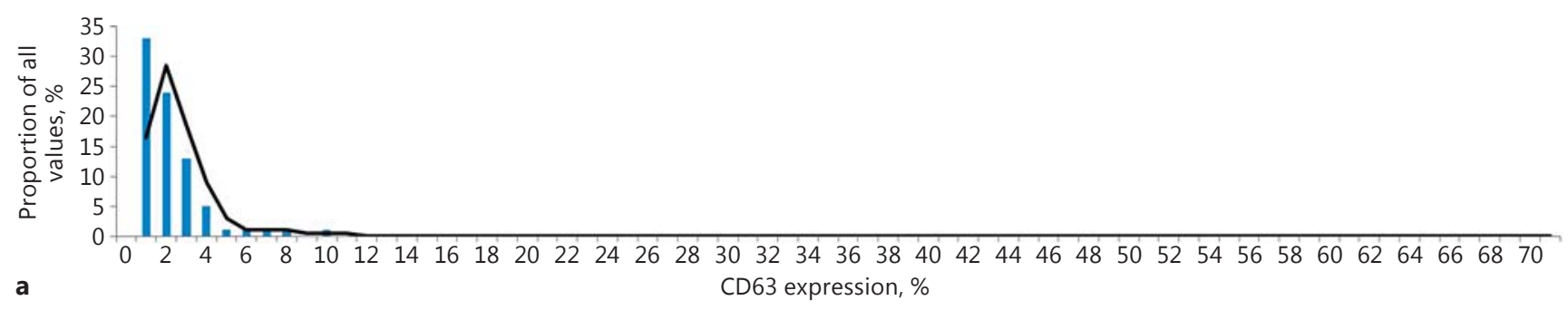

Fig. 2. CD63 distribution for controls (a), CSU patients (b), and PU patients (c). More than 50\% of the CSU patients show BAT values above $1.8 \%$. CSU, chronic spontaneous urticaria; PU, physical urticaria. 


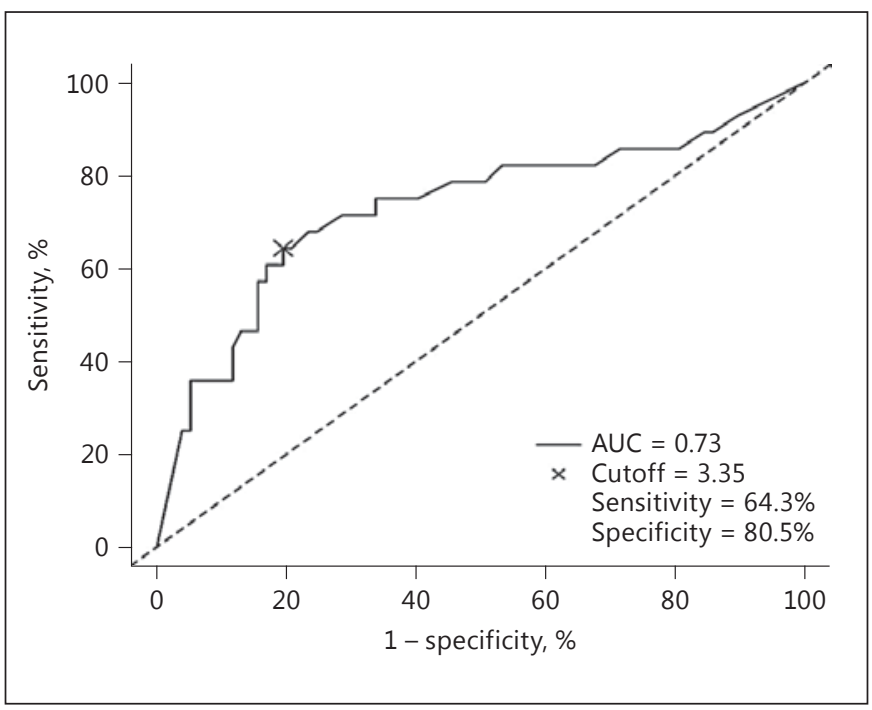

Fig. 3. CD63 as a positive marker for UAS. Area under the curve (AUC) with sensitivity and specificity for CD63 as the outcome measure predicting a worse disease severity. UAS, (weekly) urticarial activity score.

scale and outliers were removed (Fig. 1b). The log-normal distribution of CD63 was used to establish the reference range, and the cutoff for high CD63 was defined as $1.8 \%$ of $\mathrm{CD}^{+} 3^{+}$cells $(1.46 \%$; $95 \%$ CI $1.20-1.77 \%)$ once converted to a numerical scale. In the control population $(80$ patients), no association was found between CD63 levels and age, sex, ethnicity, or the presence of atopy using univariate and multivariate regression (online suppl. Table 2).

\section{BAT Results Are Elevated and More Commonly Increased in Children with CSU}

A total of 105 pediatric patients with CSU (48.6\% male, median age 8 years, 25\% IQ, 5; 75\% IQ, 12.5) were included in this study (Table 1$)$. The vast majority (96.2\%) was treated with an antihistamine, mostly on demand. The mean IgE value was $352.1 \mu \mathrm{g} / \mathrm{L}(144.3 \mathrm{kU} / \mathrm{L}$, SD $215.6 \mathrm{k} \mathrm{U} / \mathrm{L})$. The median CD63 expression was $2.1 \%$ (25\% IQ, 1.16; 75\% IQ, 5.34), significantly higher than in the control population (Wilcoxon rank 2131.5, $p<0.001$; Fig. 2a, b).

\section{High BAT Results in Children with CSU Are}

Associated with a High Disease Activity and the

Absence of Atopy

In multivariate analyses of log-normal distributed CSU patients, 2 factors were associated with CD63 levels: atopy and disease activity as assessed by the UAS7 score (online suppl. Table 2). For every increase in UAS7 by 1 score point there was an increase in CD63 by $0.1 \%$. To further assess the association between CD63 expression and the UAS7 score, CUTOFF finder software was used with CD63 as a marker and UAS7 as an outcome measure. Using this method, CD63 levels above 3.35\% were statistically significantly associated with a higher disease activity (i.e., UAS7 $\geq 15$, sensitivity, $64.3 \%$; specificity, $80.5 \%, p<0.01$; Fig. 3). Atopy was found to be inversely associated with $\mathrm{CD} 63$, and the presence of atopy reduced CD63 levels by $0.75 \%$, on average.

BAT Values in Pediatric Patients with PU Are Similar to Those in Healthy Controls

A total of 23 pediatric patients with PU (47.8\% male; median age, 11 years; 25\% IQ, 5; 75\% IQ, 16) were included in this study (Table 1). Most took antihistamines on demand (91.3\%). The mean IgE value was $947.4 \mu \mathrm{g} / \mathrm{L}$ $(388.3 \mathrm{kU} / \mathrm{L}, \mathrm{SD} 713.6 \mathrm{kU} / \mathrm{L})$. The median CD63 expression was $1.88 \%$ (25\% IQ, 0.89; 75\% IQ, 3.34). The distribution of individual CD63 values for PU patients is illustrated in Figure 2c. BAT values did not differ statistically between PU patients and controls (Wilcoxon rank sum difference, $840 ; \mathrm{p}=0.23$ ).

\section{Discussion}

We present here the first pediatric and the largest to date study assessing CD63 levels in non-CSU controls. Our study is the first to provide the reference range for the BAT, CD63 test, in non-CSU atopic and nonatopic pediatric patients and to determine the factors associated with increased levels in CSU children.

The presence of pathogenic autoantibodies in CSU was first demonstrated in 1988 with the discovery of IgG antibodies against IgE [24]. Additional IgG antibodies against the high-affinity IgE receptor (FceRI) were identified in 1993 and their capability of inducing histamine release from mast cells and basophils was documented [3]. Current data indicate that up to $40 \%$ of adult and pediatric CSU cases may be explained by the presence of these mast cell-activating antibodies [2-4].

Currently, the ASST is used as a screening tool to detect the presence of pathogenic autoantibodies in CSU patients [25]. However, this method has several pitfalls and potential limitations especially in pediatrics as discussed elsewhere [17]. Hence, attempts were made to develop in vitro diagnostic methods for the detection of 
pathogenic autoantibodies in CSU patients' sera [26]. Blood basophils and/or skin mast cells from healthy donors have been used in vitro to determine the presence and levels of functional anti-FceRIa or anti-IgE autoantibodies using the BHRA and BAT [27]. There is good concordance between assays using basophils and mast cells. Because basophils are much easier to obtain than mast cells, BHRA are currently the gold standard for the detection of functional autoantibodies in autoimmune CSU [27]. In 2006, Szegedi et al. [16] demonstrated a strong correlation between the BHRA and the BAT using the CD63 molecule as the marker for activated basophils. The advantages of the BAT include its low cost, its rapid performance, and the availability of ready-to-purchase kits, which permit standardization and reproducibility of the results (Flow Cast ${ }^{\circledR}$ Bühlmann; CU Index Test; IBT Laboratories, Lenexa, KS, USA; Anti-IgE Receptor Ab; ADx Laboratories, Denver, CO, USA; HR-Urticaria Test; RefLab, Copenhagen, Denmark) $[16,17]$.

Several BAT have been assessed in adult CSU patients, and $\mathrm{CD} 63$ and $\mathrm{CD} 203 \mathrm{c}$ are held to be the most reliable markers [27]. The advantages of CD63 include that it is the most studied marker in CSU and shows the best correlation to basophil degranulation [17]. In addition, several studies have found a very high correlation (up to 95.5\%) between the CD63 expression on basophils and the ASST in the diagnostic workup of autoimmune CSU $[28,29]$. Furthermore, CD63 expression has been suggested to be suitable for monitoring disease activity and the response to therapy in patients with urticaria and in patients with atopic disease $[18,28,30,31]$. Hence, the BAT using CD63 as the activation marker is a valuable tool in the diagnostic workup of CSU patients.

As of now, no published results of BAT studies in pediatric CSU patients are available and the reference range for normal CD63 expression in children is unknown. Studies in adult CSU patients defined the BAT cutoff as the 95th percentile of $\mathrm{CD}^{+} 3^{+}$cells induced by the serum of healthy atopic or nonatopic volunteers $[5,17,28,29]$. However, most studies do not specify if the distribution of their control values was normally distributed.

Our results demonstrate that pediatric CSU patients have significantly higher levels of CD63 BAT compared to non-CSU controls. In contrast, there was no significant difference in CD63 expression between controls and PU patients, probably because the latter exemplify episodic urticaria only in response to a particular trigger. Age, gender, ethnicity, or the presence of atopy (asthma, eczema, hay fever, or food allergies) did not influence CD63 levels in non-CSU patients. However, atopic CSU patients ap- peared to have lower CD63 scores than their nonatopic peers.

Using a cutoff of $1.8 \%$ of positive CD63 cells ( $>95 \%$ CI of the logarithmic form), $58 \%$ of our CSU cohort showed a positive BAT, one of the positivity criteria for autoimmune CSU. This is in line with previous studies in adults that used the CD63 BAT and found a $40-50 \%$ prevalence of autoimmune CSU $[5,16,28]$. Previous adult studies assessed smaller cohorts, with often less than 20 non-CSU controls, to establish the cutoff for autoimmune CSU, and the type of value distribution was generally not defined $[5,16,17,25,28]$.

In children, the prevalence of ACU was suggested to be similar to that in adults, based on the BHRA and the ASST $[2,4,32]$. To our knowledge, the BAT has not yet been validated as a diagnostic test for autoimmune CSU in children. Hence, the use of CD63 BAT as a diagnostic test for autoimmune CSU needs to be established by future studies conducted specifically in pediatric patients. Nonetheless, we have demonstrated that CD63 expression is significantly higher in pediatric CSU patients compared to non-CSU controls and PU patients and that its expression may be affected by the presence of atopy in CSU patients. Further, CD63 values above 3.4\% have a sensitivity of more than $60 \%$ and a specificity of more than $80 \%$ for predicting moderate to high disease activity. This may be clinically useful to monitor responses to therapy objectively, in addition to the use of the UAS7, which requires patient compliance. Taken together, we suggest that the CD63 BAT may be a useful test to diagnose and monitor autoimmune CSU in children.

One should keep in mind that different CD63 BAT methodologies exist and may influence the outcome. Triple-labeled flow cytometric detection of $\mathrm{CD}^{+} 3^{+}, \mathrm{CCR}^{+}$, and HLA-DR ${ }^{-}$cells has been shown to be preferable, because it allows for a high basophil recovery [27]. To further reduce basophil degranulation variability a single basophil donor should be used if feasible, or basophil donors with similar characteristics should be used. In our study, a single donor was used and results were reproduced using a second basophil donor. In contrast to atopic donor basophils, basophils from healthy donors need to be primed with IL-3, a transcription activator known to enhance specific basophil degranulation, to achieve comparable degranulation and histamine release [17, 33]. Optimum IL-3 concentrations have been previously defined and are now integrated into available CD63 BAT kits [17].

Our study has some potential limitations. The available patient sera volumes were too low to perform the DOI: $10.1159 / 000451084$
Netchiporouk/Moreau/Rahme/Maurer/ Lejtenyi/Ben-Shoshan 
gold standard BHRA to validate the CD63 BAT as a diagnostic test for autoimmune CSU in children. Future studies need to address this. Duplicate samples were only tested on 46 patients in total using basophils from different donors. While the finding of similar results is reassuring, the lack of duplicate testing on all patients constitutes a limitation in our study. It is impossible to predict whether duplicate or triplicate analysis would have prevented outliers' elimination from the study analysis. All eliminated outlier values from the CD63 cutoff calculation had a CD63 expression of $0 \%$, and hence the potential inclusion of these values would have resulted in a further decreased CD63 cutoff value. The rate of atopy (especially food allergy) was higher in our control group than in the CSU and PU groups. However, linear regression showed that atopy is not associated with CD63 expression in nonCSU subjects. Finally, given that different CD63 BAT kits may show different results, our results may only be applicable for the CD63 BAT kit we used in this study.

In conclusion, the CD63 BAT appears to be a feasible and useful tool for diagnostic workup in CSU. Its specificity and sensitivity for diagnosing autoimmune CSU in children should be assessed by a future study that in- cludes CD63 BAT and BHRA measurements, the ASST, and quantification of anti-IgE and anti-FceRI autoantibodies. The cutoff for positive CD63 likely differs in the adult population and should be addressed by future studies. The established CD63 BAT cutoff of $1.8 \%$ in children, if confirmed by future studies, may be used in the future for research and clinical practice. CD63 BAT may be also be used to assess disease activity in CSU. We are currently using the CD63 BAT to monitor disease activity and the response to treatment, to provide insights on how this test may help to improve the management of CSU.

\section{Acknowledgements}

Dr. Ben-Shoshan is a recipient of the Allergen Emerging Clinician Scientist award and the FRSQ 1, awards which have funded this project. This study was supported by a Canadian Dermatology Foundation Research Grant to Dr. Elena Netchiporouk.

\section{Disclosure Statement}

The authors have no conflicts of interest to disclose.

\section{References}

1 Zuberbier T, Aberer W, Asero R, BindslevJensen C, Brzoza Z, Canonica GW, Church MK, Ensina LF, Gimenez-Arnau A, Godse K, Goncalo M, Grattan C, Hebert J, Hide M, Kaplan A, Kapp A, Abdul Latiff AH, MathelierFusade P, Metz M, Nast A, Saini SS, SanchezBorges M, Schmid-Grendelmeier P, Simons FE, Staubach P, Sussman G, Toubi E, Vena GA, Wedi B, Zhu XJ, Maurer M; European Academy of Allergy and Clinical Immunology; Global Allergy and Asthma European Network; European Dermatology Forum; World Allergy Organization: The EAACI/ GA(2) LEN/EDF/WAO guideline for the definition, classification, diagnosis, and management of urticaria: the 2013 revision and update. Allergy 2014;69:868-887.

2 Brunetti L, Francavilla R, Miniello VL, Platzer MH, Rizzi D, Lospalluti ML, Poulsen LK, Armenio L, Skov PS: High prevalence of autoimmune urticaria in children with chronic urticaria. J Allergy Clin Immunol 2004;114:922927.

3 Hide M, Francis DM, Grattan CE, Hakimi J, Kochan JP, Greaves MW: Autoantibodies against the high-affinity $\operatorname{IgE}$ receptor as a cause of histamine release in chronic urticaria. N Engl J Med 1993;328:1599-1604.
4 Sahiner UM, Civelek E, Tuncer A, Yavuz ST, Karabulut E, Sackesen C, Sekerel BE: Chronic urticaria: etiology and natural course in children. Int Arch Allergy Immunol 2011;156: 224-230.

5 Altrich ML, Halsey JF, Altman LC: Comparison of the in vivo autologous skin test with in vitro diagnostic tests for diagnosis of chronic autoimmune urticaria. Allergy Asthma Proc 2009;30:28-34.

6 Grattan CE, Wallington TB, Warin RP, Kennedy CT, Bradfield JW: A serological mediator in chronic idiopathic urticaria - a clinical, immunological and histological evaluation. Br J Dermatol 1986;114:583-590.

7 Greaves MW, Tan KT: Chronic urticaria: recent advances. Clin Rev Allergy Immunol 2007;33:134-143.

8 Konstantinou GN, Asero R, Maurer M, Sabroe RA, Schmid-Grendelmeier P, Grattan CE: EAACI/GA(2)LEN task force consensus report: the autologous serum skin test in urticaria. Allergy 2009;64:1256-1268.

9 Sabroe RA, Grattan CE, Francis DM, Barr RM, Kobza Black A, Greaves MW: The autologous serum skin test: a screening test for autoantibodies in chronic idiopathic urticaria. Br J Dermatol 1999;140:446-452.
10 McGowan EC, Saini S: Update on the performance and application of basophil activation tests. Curr Allergy Asthma Rep 2013;13:101109.

11 Schroeder JT: Basophils: emerging roles in the pathogenesis of allergic disease. Immunol Rev 2011;242:144-160.

12 Ebo DG, Bridts CH, Hagendorens MM, Aerts NE, De Clerck LS, Stevens WJ: Basophil activation test by flow cytometry: present and future applications in allergology. Cytometry B Clin Cytom 2008;74:201-210.

13 Knol EF, Mul FP, Jansen H, Calafat J, Roos D Monitoring human basophil activation via CD63 monoclonal antibody 435. J Allergy Clin Immunol 1991;88:328-338.

14 Dvorak AM, MacGlashan DW Jr, Morgan ES, Lichtenstein LM: Vesicular transport of histamine in stimulated human basophils. Blood 1996;88:4090-4101.

15 Furuno T, Teshima R, Kitani S, Sawada J, Nakanishi M: Surface expression of CD63 antigen (AD1 antigen) in P815 mastocytoma cells by transfected ige receptors. Biochem Biophys Res Commun 1996;219:740-744.

16 Szegedi A, Irinyi B, Gal M, Hunyadi J, Danko K, Kiss E, Sipka S, Szegedi G, Gyimesi E: Significant correlation between the CD63 assay and the histamine release assay in chronic urticaria. Br J Dermatol 2006;155:67-75. 
17 Gentinetta T, Pecaric-Petkovic T, Wan D, Falcone FH, Dahinden CA, Pichler WJ, Hausmann OV: Individual IL-3 priming is crucial for consistent in vitro activation of donor basophils in patients with chronic urticaria. J Allergy Clin Immunol 2011;128:1227-1234 e1225.

18 Netchiporouk E, Nguyen $\mathrm{CH}$, Thuraisingham T, Jafarian F, Maurer M, Ben-Shoshan M: Management of pediatric chronic spontaneous and physical urticaria patients with omalizumab: case series. Pediatr Allergy Immunol 2015;26:585-588.

19 Hoffmann HJ, Santos AF, Mayorga C, Nopp A, Eberlein B, Ferrer M, Rouzaire P, Ebo DG, Sabato V, Sanz ML, Pecaric-Petkovic T, Patil SU, Hausmann OV, Shreffler WG, Korosec P, Knol EF: The clinical utility of basophil activation testing in diagnosis and monitoring of allergic disease. Allergy 2015;70:1393-1405.

20 Ben-Shoshan M, Kagan R, Primeau MN, Alizadehfar R, Turnbull E, Harada L, Dufresne C, Allen M, Joseph L, St Pierre Y, Clarke A: Establishing the diagnosis of peanut allergy in children never exposed to peanut or with an uncertain history: a cross-Canada study. Pediatr Allergy Immunol 2010;21:920926.

21 Sussman G, Hebert J, Gulliver W, Lynde C, Waserman S, Kanani A, Ben-Shoshan M, Horemans S, Barron C, Betschel S, Yang WH, Dutz J, Shear N, Lacuesta G, Vadas P, Kobayashi K, Lima H, Simons FE: Insights and advances in chronic urticaria: a Canadian perspective. Allergy Asthma Clin Immunol 2015; 11:7.
22 Budczies J, Klauschen F, Sinn BV, Gyorffy B, Schmitt WD, Darb-Esfahani S, Denkert C: Cutoff finder: a comprehensive and straightforward web application enabling rapid biomarker cutoff optimization. PLoS One 2012; 7:e51862.

23 Khalil A MD, Gimenez-Arnau A, Grattan C, Balp M, Stull D: Weekly urticaria activity score (UAS7) and dermatology life quality index (DLQI) in validation of chronic spontaneous/idiopathic urticaria (CSU/CIU) health states. Am Acad Allergy Asthma Immunol Annu Meet, Houston, 2015.

24 Gruber BL, Baeza ML, Marchese MJ, Agnello V, Kaplan AP: Prevalence and functional role of anti-IgE autoantibodies in urticarial syndromes. J Invest Dermatol 1988;90:213-217.

25 Irinyi B, Gyimesi E, Garaczi E, Bata ZS, Kemeny L, Zeher M, Remenyik E, Szegedi A: Extended diagnostic value of autologous serum skin test and basophil CD63 expression assay in chronic urticaria. Br J Dermatol 2013;168: 656-658.

26 Tong LJ, Balakrishnan G, Kochan JP, Kinet JP, Kaplan AP: Assessment of autoimmunity in patients with chronic urticaria. J Allergy Clin Immunol 1997;99:461-465.

27 Konstantinou GN, Asero R, Ferrer M, Knol EF, Maurer M, Raap U, Schmid-Grendelmeier P, Skov PS, Grattan CE: EAACI task force position paper: evidence for autoimmune urticaria and proposal for defining diagnostic criteria. Allergy 2013;68:27-36.
28 Frezzolini A, Provini A, Teofoli P, Pomponi D, De Pita O: Serum-induced basophil CD63 expression by means of a tricolour flow cytometric method for the in vitro diagnosis of chronic urticaria. Allergy 2006;61:1071-1077.

29 Gyimesi E, Sipka S, Danko K, Kiss E, Hidvegi B, Gal M, Hunyadi J, Irinyi B, Szegedi A: Basophil CD63 expression assay on highly sensitized atopic donor leucocytes-a useful method in chronic autoimmune urticaria. Br J Dermatol 2004;151:388-396.

30 Nopp A, Johansson SG, Ankerst J, Bylin G, Cardell LO, Gronneberg R, Irander $\mathrm{K}$, Palmqvist $\mathrm{M}$, Oman $\mathrm{H}$ : Basophil allergen threshold sensitivity: a useful approach to anti-IgE treatment efficacy evaluation. Allergy 2006;61:298-302.

31 Rodriguez-Trabado A, Fernandez Pereira LM, Romero-Chala S, Garcia-Trujillo JA, Camara Hijon C: Monitoring omalizumab treatment efficacy in chronic urticaria by the basophil activation test. Allergol Immunopathol (Madrid) 2012;40:390-392.

32 Chansakulporn S, Pongpreuksa S, Sangacharoenkit $\mathrm{P}$, Pacharn $\mathrm{P}$, Visitsunthorn N, Vichyanond $\mathrm{P}$, Jirapongsananuruk $\mathrm{O}$ : The natural history of chronic urticaria in childhood: a prospective study. J Am Acad Dermatol 2014; 71:663-668.

33 Ochensberger B, Daepp GC, Rihs S, Dahinden CA: Human blood basophils produce interleukin-13 in response to IgE-receptor-dependent and -independent activation. Blood 1996;88:3028-3037. 